\title{
Understanding the B2B E-Market in China
}

\author{
Jing Zhao, Frank Duserick, Wilfred V Huang \\ Jing Zhao: \\ Center for International Cooperation in E-Business \\ College of Management \\ China University of Geosciences \\ Wuhan 430074, P.R.China \\ yuzp@cug.edu.cn, zhao5563@yahoo.com.cn \\ Frank Duserick and Wilfred V Huang: \\ College of Business \\ Alfred University \\ Alfred, NY 14802, U.S.A. \\ \{fduserick, fhuang\}@alfred.edu
}

\begin{abstract}
This paper seeks to develop a conceptual model that is inherently suitable for analyzing the complexity of $\mathrm{B} 2 \mathrm{~B}$ e-market and transaction performance in China. The case study of CCEC.com provides an insight on how one excellent $\mathrm{B} 2 \mathrm{~B}$ e-market has executed a successful strategy utilizing the existing source within the current business climate of China. The data from the case research illustrate e-commerce strategies and crucial business activities. Further, the B2B E-Market Model is proposed for studying the critical strategy component of value creation in e-markets of China. The Model involves with two variables: the e-commerce process and the controlling complexity. Building on process insight, the e-commerce process can be modelled by separating main business activities into four phases designed to exploit value creation opportunity. Controlling complexity refers to supervising and controlling the transactional processes for security, trust and efficient transaction environment. The Model illustrates the relationship between the business components required to support the e-commerce processes with the value creation factor and the controlling complexity. Using the model in comparisons of B2B e-markets in USA and in China, we find unique characteristics in transactional processes - the information, negotiation, payment and delivery phases. It offers an effective approach to studying dynamic structure of transactional process and a high performance e-commerce strategy.
\end{abstract}




\section{Introduction}

The application of Internet technologies to interfirm transactions has led to the amazing growth of Internet-based business-to-business (B2B) e-markets and online $B 2 B$ sales. Worldwide, according to the Gartner Group, the value of B2B Internet commerce sales transactions surpassed $\$ 433$ billion in 2000 , a 189 percent increase over 1999 sales transactions [1]. B2B market assembles numerous buyers and sellers for on-line transaction. Both sides "know "each other through issuing and searching of business information, then negotiation and completing a contract over the Internet. It creates a new trade mechanism at a highly efficient and effective manner. As business-to-business transactions are increasing on the Internet, it is becoming critical for firms to rely on Web-based supply chains or e-supply chains in order to provide almost real-time response to market conditions $[2,3,4,5,6,7]$.

According to a research report from Deloitte Research, only about 400 of today's more than 1,500 e-marketplaces are likely to succeed over the next three to four years [8]. Observing and experiencing the dramatic changes in the arena of $\mathrm{B} 2 \mathrm{~B}$ e-commerce, both academic researchers and Internet market makers are wondering what B2B business models will lead to lasting success in the digital economy [9].

The purpose of this paper is to fill a void in the research on B2B e-markets in China. We seek to develop a conceptual model that is inherently suitable for analyzing the complexity of $\mathrm{B} 2 \mathrm{~B}$ e-market and transaction performance. We have analyzed the development of Chinese e-markets and barriers when implementing ecommerce strategies, and identified unique characteristics in the transactional processes and market mechanisms. Building on the process insight, we studied the activities, strategies, and governance of transactional processes of B2B e-market using a case study approach. Furthermore, the paper proposes a B2B E-Market Model for the current limiting conditions of China. In the model, the whole transactional process can be viewed as the e-commerce process with four phases focusing on the controlling complexity and the value creation factors. This enables us to capture and study e-commerce strategies and primary e-commerce activities in each phase, which have a direct impact on value creation in the environment of China. We also discussed the e-markets in U.S.A and China using the B2B E-Market Model. We found many characteristics in common with the different maturity level in applying information technology on transactional processes. Our finding offers an efficient way of studying $\mathrm{B} 2 \mathrm{~B}$ e-market so as to explore e-commerce strategies and the adopted innovative market mechanisms directed towards the needs of customers.

\section{Background}

\subsection{Literature Review}

We review the academic literature on B2B e-market in management journals of China (i.e., Management Review, Shanghai Management Science, Technoeconomics 
\& Management Research) within the past three years. The literature on B2B emarket is limited, and main opinions are summarized as following:

Zhu [10] present that three modes of B2B market from a B2B market management perspective. They are: (1) E-Market controlled by sellers means that the suppliers create their webpage and products catalog by themselves to attract more buyers and reduce the transaction costs. (2) E-Market controlled by buyers means that the buyers create webpage and put their products on B2B e-Market by themselves to attract more suppliers and reduce the transaction costs. (3) E-Market controlled by intermediary means that E-Market play the role of digital intermediaries $[11,12]$. For example, demand and supply information can be aggregated and disseminated, and buyers and sellers can be matched in E- markets, and to make transaction at the marketplace for increasing transaction efficiency and reducing transaction costs for both parts. He states that intermediary E-Market provides the platform for small and medium sized enterprises which can't establish their own company website, and for large enterprises which realize the integration of interior ERP/MRP/MIS with exterior exchange markets.

Wang et al. [13] proposed a neutral B2B E-Market model consisted of transaction opportunity, transaction verifying and transaction executing. The research presented the categories, content and construction of the model, which provide a useful reference for market markers in neutral B2B E-Market.

Jiang [14] proposed a framework of B2B E-procurement which is controlled by B2B intermediary. The greatest advantages of this model are improving efficiency, reducing transaction costs. The platform integrated the different suppliers and purchasers into the e- market, which has greatly facilitated finding products and the selection of suppliers who can more easily promote their products. This not only reduces the cost of sales, but also can handle inventory and make an inventory of assets.

Yan et al. [15] explored the mechanisms for building reliable transaction between sells and buyers under the environment of B2B E-market. A theoretical framework is proposed for reliable transaction system includes credit control, credit appraisal, credit obligation, credit feedback and cooperation criterion.

In summary of literature found, although prior work in this field has substantially contributed to our understanding of the role of e-market in China, we think existing works are scarce on case studies in choosing and implementing the best e-business strategy, and also on the process of practical transaction in an e-marketplace.

\subsection{The Electronic Markets in China}

The Chinese government has always been aware of the impelling effect of B2B ebusiness on the economy and the capabilities of the organization, and has been actively building a nationwide infrastructure of data communication network since 1993. Today, the existing network infrastructure reaches more than 2200 cities and towns. With the infrastructure in place, the government has built several advanced and unified public data and multimedia communication platforms that form a 
national Internet backbone network [16]. Entering 1998, government ministries and some forward-thinking IT firms spearheaded the e-commerce development by creating commercially oriented derivatives of the existing Internet backbone networks. The networks emerged as the B2B electronic markets. Their roles include aggregating suppliers and buyers, and providing trust and market information. For examples: [17]

- China International e-Commerce Network serves as a window through which businesses can get the latest information on foreign trade policy, management practices, government legislation and regulation, as well as general market environment.

- China Materials Information Center updates the availability of raw material, equipment and other inputs of production, so that businesses can derive economic benefit from otherwise idle resources.

- China Crops Exchange Network provides valuable information on the world crops market, and currently supports on-line trading in parts of China.

- China National Commodity Exchange Center, China Economic Information Network, Chinamarket, collectively form a virtual exchange, facilitating the flow of goods.

- National Inventory Adjustment Network, built by the Ministry of Interstate Commerce, has been effective in increasing inventory turnover and improving the utilization of capital.

- Others include China Commercial Airlines Reservation System, China Securities and Investment Information Network, China Futures Information Network, China On-Line Banking System in addition to Beijing e-commerce Project and Shanghai Information Center.

These networks form the basis for the early development of E-business in China. They relieve businesses of substantial initial investment, yet provide them opportunity to experiment with and understand e-commerce. As the forerunner of the transition to e-commerce, the entrepreneurs who were mostly small-and-mediumsized-enterprises (SME) have derived substantial profit from the use and exchange of information on the network. China is in the midst of industrialization, modernization and informationization. Various aspects of the consumer economy such as purchase habits, modes of exchange, and payment methods lag those of the developed countries. Information technology is not yet widely deployed in enterprises. It is expected that the development of full-scale e-commerce processes in B2B e-markets will encounter many obstacles [18]

First, there is a lack of solid understanding about e-commerce among managers. Business alliances and partnerships are dominated by longstanding personal "oldboy" connections. Moreover, the enterprise information system is under-utilized. A random sample of 1300 managers in 520 large state-owned enterprises and local backbone enterprises released by the National Council on Economics and Commerce in 2001 indicates that 69.1 percent of businesses host their own web sites, 21.6 percent of enterprises have a proposed e-commerce strategy, 4.1 percent of them completed procurement over the Internet and 3.4 percent of them engaged in Internet marketing [19].

Second, while the financial system in China is being modernized, electronic payment systems and the associated regulations are not yet in place. Some purchases 
for small-size enterprises are still made with cash. Many of the legal issues associated with e-commerce have not been addressed [20]. Third, inefficient transportation systems and the absence of professional distribution outsourcers are preventing businesses from going completely on-line since they must provide distribution capabilities on their own.

Under these limiting conditions, the development of electronic markets has unique characteristics in the transactional process, which relate largely to the current industry structure, financial infrastructure and organization structure.

\section{A Case}

The most prominent B2B e-market in China is China National Commodity Exchange Center (CCEC). Using the resources of the "Gold trade" project supported by government ministries, CCEC.com shows evidence of significant successes as an online B2B Exchange in China through its on-line transactional processes. So we are particularly interested in its development of the transactional process and the security and trust perceived by its buyers and sellers in the e-market.

\subsection{Data collection:}

In about 1999-2001, CCEC put its transaction volume for on-line sales and off-line sales over its website every day. So we often log on its website to get information. In addition data was gathered about transaction and sales volumes. Interviews with corporate executives and observation of transaction processing mechanisms were the bases for data collection. We get information from talking with one corporate executive at the conferences and through phone calls in 1999-2001. We also get materials about introduce to CCEC transaction processing from $C D$ attached with a book written by Jiang, X.P. in 1999 [21]. Other sources were from corporate brochures at its website, newspapers/magazine report and public information websites like Juns.com [17]. Relative data were reported as following: CCEC, an on-line B2B Exchange firm in China, initiatives its B2B e-commerce early in 1997. Its total registered members, both current and past, exceed five million. The B2B exchanges offer more than 500 classified products in all 26 industries for its members to look up and choose. It has the capability to not only collect and distribute extensive information about commodities and enterprises but also to provide various trade functions such as on-line negotiations, signing agreements, inviting tenders, bidding, purchasing and selling, settlement, and distribution. In the first two months of 2003, transaction volume for on-line sales reached 3.9 million dollars and off-line sales 30.7 million [22]. On-line sales transactions indicate that buyer and seller immediately complete the whole transactional processes through the CCEC's B2B Exchange e-commerce system, 
including the processes of e-Procurement, payment, and delivery of digital products. The main characteristic of on-line transactions is that all the transactional processes are completed on-line. Off-line sales transactions signify that both sides sign contracts over a Web site but the payment and goods delivery are completed traditionally. Using the resources of the "Gold trade" project supported by government ministries, CCEC.com shows evidence of significant successes as an online B2B Exchange in China through on-line transactional processes.

\subsection{CCEC's e-commerce activities and strategies}

In China, security and trust are the most significant factors for successful e-market that attract buyers and sellers to make on-line trading. It is a complex and difficulty issue that will require cooperation of bank, transportation department and quality inspection department to establish a secure and reliable B2B e-market environment. Let's look CCEC how to do. Since CCEC is supported by the government, it has the ability of supervising and controlling all transactional processes. CCEC ensures the security of buyers' money and sellers' products using an application suite of normative bylaws, scientific management methods, and other comprehensive services. The advantage of CCEC, and also the key to its success, is that its integrated operation has enabled a complete solution to monitoring the credibility of both buyer and seller.

This study mainly explores CCEC's special transactional processes through two dimensions: the process and control. The process dimension divides e-commerce activities into several phases that provide a basis to develop a clear understanding of e-commerce activities at each phase and why and how e-market maker adopt an ecommerce strategy at each phase. The control dimension includes supervising and controlling of transactional process for Security and Trust for successful B2B emarket in China.

E-market can be modeled by classifying commerce activities into several phases. For instance, Selz and Schubert [23] refer to the four phases in their model as information, agreement, settlement, and communication. In this study, according to connected sequenced of the online transaction process, we divide CCEC's activities into four phases: information, negotiation, payment, and delivery that construct a completed transaction process. E-commerce activities are analyzed within the phase. The major concern is to carry out the contract deal safely and reliably in the transactation process. Using data from the CCEC.com web site, Table 1 illustrate CCEC.com's main e-commerce activities and strategies within the context of the four phases. The controlling complexity and the process dimension make us can pay attention to CCEC.com how to realize Security and Trust in the phase of transaction process. It provides an insight on the execution of this successful strategy in the current business climate of China. Let's analyze CCEC.com's e-commerce activities and strategies in each phase as following: 


\begin{tabular}{|c|c|c|c|}
\hline $\begin{array}{c}\text { E-commerce } \\
\text { Process }\end{array}$ & $\begin{array}{l}\text { Controlling } \\
\text { Complexity }\end{array}$ & CCEC.com's e-commerce activities & Strategy \\
\hline Information & Low & $\begin{array}{l}500 \text { classified products, } 5 \text { million } \\
\text { registered members, Business Express, } \\
\text { Sample House, Members' Office, Enable } \\
\text { customers to manage and govern } \\
\text { information and transaction. }\end{array}$ & $\begin{array}{c}\text { Personalized and } \\
\text { Customized } \\
\text { Services }\end{array}$ \\
\hline Negotiation & Medium & $\begin{array}{l}\text { Various trade functions, signing } \\
\text { agreement, inviting tenders and bidding. } \\
\text { On-line catalogs, on-line "Negotiation } \\
\text { Room" and "Sample House" services to } \\
\text { match seller with buyer }\end{array}$ & $\begin{array}{c}\text { Personalized and } \\
\text { Customized } \\
\text { Services }\end{array}$ \\
\hline Payment & High & $\begin{array}{l}\text { Support } 5 \text { payment methods based on } \\
\text { entire payment processes integrating } \\
\text { order, purchasing, warehouse and } \\
\text { shipping information and emphasis on } \\
\text { neutral supervisor role, and collaboration } \\
\text { and information exchange }\end{array}$ & $\begin{array}{l}\text { Structure and } \\
\text { Control of the } \\
\text { Payment Process }\end{array}$ \\
\hline Delivery & High & $\begin{array}{l}\text { Delivery networks consist of } 200 \\
\text { branches in } 40 \text { provinces and cities of } \\
\text { China. Shipping tracking system, } \\
\text { Coexistence of market partners' alliance } \\
\text { and government governance }\end{array}$ & $\begin{array}{c}\text { Strategic partners } \\
\text { network }\end{array}$ \\
\hline
\end{tabular}

Table 1 CCEC.com's e-commerce activities and strategies

\section{CCEC.com Personalized and Customized Services}

In the information and the negotiation phases, CCEC.com offers personalized and customized services to meet the unique needs of each customer. Because the number of registered members in CCEC.com has increased dramatically from 9000 to 5 million between 1999 and 2002, customers from different backgrounds (small or large size buying enterprises) expect much flexibility in choosing sellers and products, and much control in building and operating their own on-line transaction. In the information phase, CCEC.com offers a "Members' office", which enables customers to have their own office for managing and governing their business information. CCEC.com customers can control, revise, change, or dispose of their business information including registration, issuance, counter offers, partners' offers, contracts signed, and trade codes.

At the same time, in the negotiation phase the combination of on-line catalogues and on-line negotiation and "Sample House" services new opportunities are created, 
in less time and effort, to match sellers with buyers. This e-transaction benefits both customer and manager. It is worth noting that customers can play a critical role in value creation. They may work with the manager of B2B Exchange to manage and control information and transactions. The degree of participation of customers depends partially on the quality of personalized service provided in the Electronic markets.

\section{- CCEC.com Structure and Control of the Transactional Process}

In the payment and the delivery phases, CCEC.com's payment process is operated as a transactional process including financial settlement and delivery. It involves multiple players from transportation and storage providers to customs agents and banks. CCEC.com and its branches act as a neutral manager. Banks and transport companies are their partners along the payment channel.

The structure of the transactional process involves CCEC, bank, buyer, and seller as actors. After signing the contract, both buyer and seller pay a transaction fee and deposit to bank partner. CCEC.com initiates by notifying seller to deliver the goods. After the delivery, the seller sends a bill of lading to the local CCEC branch. CCEC.com then notifies the buyer to pay money to the bank. When payment is confirmed the bank informs CCEC.com. The local CCEC branch is then being notified and sends the bill of lading to the buyer to verify the goods. This involves the buyer to receive the goods and to confirm no discrepancy from the contract. The buyer then informs CCEC.com for settlement. In the last step, CCEC.com informs the bank and transacts settlement. The structure map of the payment process showed in Figure 1.

In the process, the B2B Exchange e-commerce system facilitates information flow between CCEC.com and all participants, and supports on-line transaction settlement. The structure of e-payment process, with emphasis on the neutral supervisor role, relies on collaboration and information exchange among participants. It provides a reliable, secure and efficient transaction environment under controlled conditions. In China this transactional process is especially useful because intentionally delayed shipments and payments occasionally occur.

- CCEC.com strategic partners network

Based upon the success of CCEC's B2B prototype, developed with the support of the "Gold Trade" project launched jointly by 13 ministries and commissions, CCEC.com now develops and guides affiliated branches that are managed by the provincial economic and trade councils. These branches form strategic alliances with banks, financial institutions and other trade fulfillment partners (quality assurance, insurance and delivery companies), and initiate joint-ventures with IT companies and local government agencies for special exchange markets, such as www.xhoi.com.cn, a web site of the Xin Hua Bookstore, and js.ccec.com, the crops exchange managed by government of Kirin Province. The appearance of a strategic network in which market and government governance mechanisms coexist has significantly expanded CCEC.com's market and customer bases. Moreover, CCEC.com's brand awareness and reputation are increasing rapidly. 


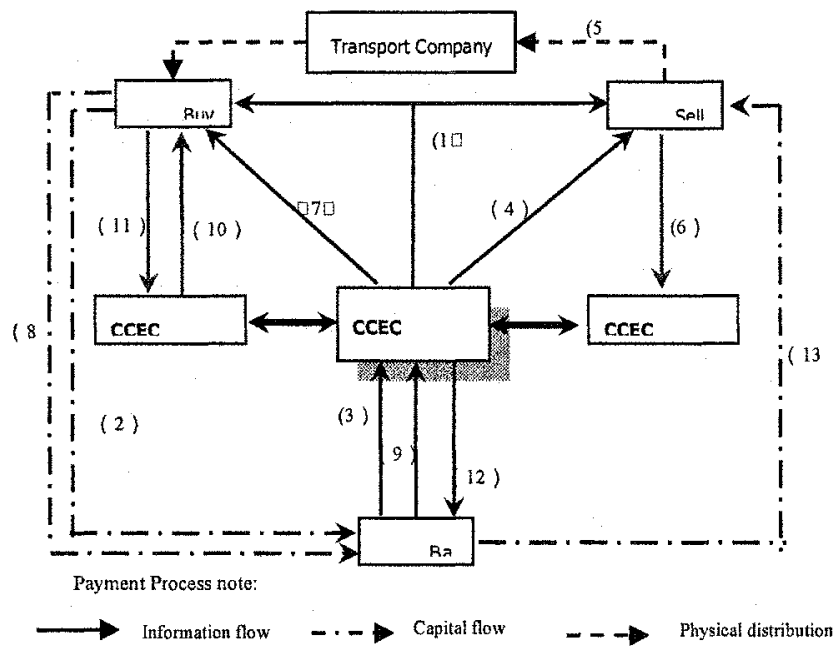

1. Sign contract 2, Pay Deposit 3. Transmit unformation 4. Ask for Delivery 5. Deliver Goods

6. Bill of Lading 7. Ask for Payment 8. Pay Monoy 9. Transmit Information 10. Transmit Bill and Receipt

11. Verify Report 12. Ask for Settle

Fig. 1. CCEC Payment Process

\section{The B2B E-Market Model}

Previous research papers in B2B E-Market mostly are in terms of their roles and functions [9].A major objective of this paper is to identify and study the activities and strategies performed by $\mathrm{B} 2 \mathrm{~B}$ e-markets maker. It is through their activities and strategies that $\mathrm{B} 2 \mathrm{~B}$ e-markets provide a secure and reliable $\mathrm{B} 2 \mathrm{~B}$ transaction process for their customers and generate revenue for themselves. The B2B E-Market Model (Figure 2) was derived from the case study in CCEC. It can be used to study and characterize the activities and strategies of B2B e-markets in each phase of the process so as to explore significant factors for successful e-market.

The advantage of CCEC, and also the key to its success, is that it has the ability of supervising and controlling all transactional processes and has enabled a complete solution to monitoring the credibility of both buyer and seller. So the proposed B2B E-Market Model involves two variables: the e-commerce process and the controlling complexity. According to connected sequences of transaction process, the ecommerce process is divided into four phases: information, negotiation, payment, and delivery. It enables us to capture and study e-commerce activities and strategy in each phase, which has a direct impact on value creation. Controlling complexity refers to supervising and controlling transactional processes for a secure and reliable $\mathrm{B} 2 \mathrm{~B}$ transaction environment. The current electronic markets in China are beginning to emphasize the capabilities that aim to satisfy management transaction and reliable e-commerce processes needs. The whole process is designed with supervising and 
controlling features facilitated by the web technology, and the creation of a coparticipation partners' network linking over the Internet for transaction process support. The controlling complexity degree varies among the four phases. The indication of the degree is from "low" to "high". For example, in the information phase, there is a low controlling complexity degree in facilitating this communication. Inexhaustible data about all sorts of buying and selling business is aggregated and disseminated. It is simple and straightforward to fulfill this function with Internet technology. All e-markets in China have this basic capability. The payment and delivery phases entail an end-tomend goods delivery and monetary transaction from the supplier to the buyer, and information and services among multiple players involved in the process. Shipment of bulk commodities involves multiple players from various transportation and storage providers, to freighter forwarders and surveyors, to customs agents and banks. The e-market has to coordinate all the players during the payment and shipping process so that the right information is delivered to the right person at the right time, and to supervise the execution of the transaction in a secure and reliable manner. This leads to greater flexibility and better control of information transmitting among buyer, supplier and partners by using the Web technology. It is necessary to create a partner network over the Internet to accomplish collaboration management, so there are highcontrolling degrees of complexity in both phases. In e-commerce, payment and delivery processes must be exact to satisfy the seller-buyer relationship. Consequently, these two processes require intense scrutiny to ensure both parties are satisfied with the final exchange.

In the B2B E-Market Model (Figure2), the e-commerce process is divided into four phases at the horizontal axis. The vertical axis indicates the controlling complexity. The dual-axis interface plane signifies the value creation factor corresponding to each phase. The Model illustrates the relationship between the business components required to support the e-commerce processes with the value creation factor and controlling complexity. The Model aims at secured and reliable ecommerce processes that deliver significant business value, ranging from strategic challenges to operational efficiency and effectiveness issues. The Model offers a relevant perspective for exploring critical strategy components of value creation.

The value creation factors in the four phases along with the present business climate are outlined as follows:

\section{Information Phase: Providing high reach and richness of information}

In the information phase, inexhaustible information about business transactions and collaboration can be aggregated and disseminated. The crucial duties for the e-market involve managing information content, providing the appropriate classified information, and helping buyers and sellers to issue and obtain information more quickly and easily.

- Negotiation Phase: Matching buyers with sellers and creating exchange mechanisms

Electronic market managers integrate IT technologies such as on-line negotiations, agreement signing, inviting tenders, bidding, exchanging recorders, and helping to match buyers with sellers for making transactions. The principal challenges facing e-market are to lay down 
rules of exchange that are rooted in a neutral and effective process to create a fair and efficient negotiation experience for the customers.

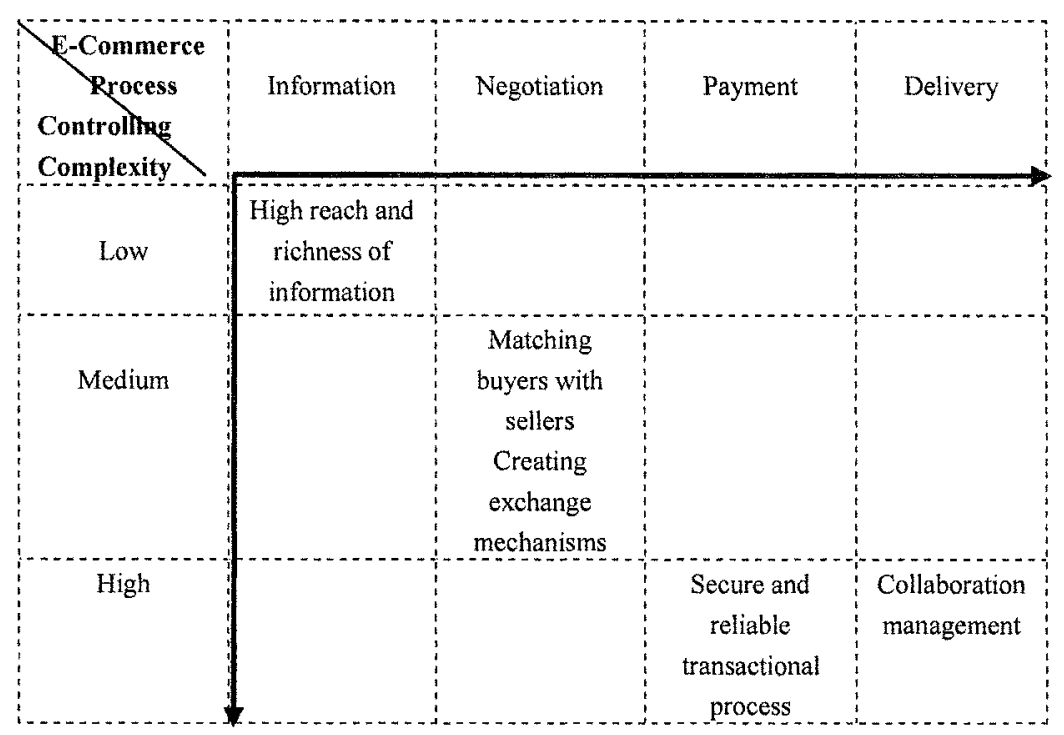

Fig. 2.: B2B E-Market Model

- Payment Phase: Secure and reliable transactional process

In the payment phase, monetary transactions occur between the buyers and sellers. The transaction activity in the payment phase, with a strong emphasis on secure and reliable payment processes, relies on the facilities for settlement of on-line transaction as well as supporting a range of payment methods offered by various financial institutions. While the financial system in China is being modernized, the e-market needs to be creative in identifying alternative expedient consumer payment processes in order to build a competitive advantage. As a developing nation China does not yet possess an e-payment infrastructure common in developed countries.

- Delivery Phase: Collaboration management

The delivery phase entails an end-to-end goods delivery from the supplier to the buyer. Together with payment phase, they form the transactional process. Thus shipment of bulk commodities involves multiple players from various transportation and storage providers to customs agents and banks. From the e-market manager's perspective, a critical issue is the lack of specialized nationwide delivery channels in China. As an emerging industrial economy, China does not yet have the supply chain 
infrastructure to support on-line commerce in an effective and efficient manner. A critical challenge for managers has been the ability to ensure the smooth flow of information, products and services among multiple players involved in the delivery process and payment phases. Inherent in this challenge is the need to increase the speed, control, and reliability of the transactional process.

The value creation factors are complete with respect to certain aspects of business component found in the four phases, they are commensurate with the controlling complexity associated with the use of IT and partner network. The information phase and the negotiation phase are characterized by management of high reach and richness of information, and by a focus on matching buyers with sellers for making transactions and creating exchange mechanisms. The payment phase and the delivery phase are characterized by the management of new forms of collaboration among all the players during the transactional process. Both emphasize the processes that enable transaction and transaction governance. It is noticeable that the e-market value generation is associated with designing, building and managing e-commerce process.

With the unique nature of e-commerce of China the Model is the conceptual basis for analyzing and understanding the primary e-commerce activities and the innovative e-commerce strategies of electronic market in emerging markets.

\section{Discussion}

The B2B E-Market Model is used to analyze other electronic markets in the world, which managers can rely upon to enhance their understanding of future developments in this arena. First; let's characterize two of the e-markets in USA, eChemical and PlasticsNet, through the analytical lens of four phases of the B2B EMarket Model. Then, we will make comparisons of characteristics and regulations of e-markets in China and USA. It is found that (a) they have common characteristics, (b) they are concerned with the security and swiftness of the trade procedure, and (c) they focus on establishing partnership.

\section{1 e-Chemical}

e-Chemical (www.e-chemicals.com) is a chemical articles trade leading e-commerce company of U.S.A. It has greatly improved the security and reduced the time in purchasing, sales and deliveries. It was established by Alf Sherk, Lorne Darnell and Yossi Sheffi in the autumn of 1998, and the members must be the purchase traders and suppliers who obtained the qualification in the chemical trade. The creation of eChemical electronic market is to solve the challenge of purchasing in the chemical trade. The reason is mainly due to a widely scattered market causing poor efficiency and staggering prices in purchasing. The management group of e-Chemical electronic market, with more than 150 years of experience in the chemical trade organization, production and sales, put forward a set of comprehensive solutions to the trade and solve this supply-chain problem. 
Information phase:

In the information phase of the B2B E-Market Model, e-Chemical has abundant of information. In the October of 1999, e-Chemical listed more than 1000 kinds of goods on the network, registered 600 buyers and 20 manufacturers and suppliers. Besides the general product information, e-Chemical offers the trade news and special reports to people every day, the contents of which are all closely related to chemical industry and e-commerce trade. There are feedback mechanisms on the website, allowing customers to ask questions. It keeps the website robust by adding service items constantly like environment, health, etc.

\section{Negotiation Phase:}

e-Chemical's website allows buyers to select, buy, inquire for price, order and consign. It has comprehended the connection between factories by allowing large volume purchasing on the web, therefore accelerating the course of purchase greatly.

\section{Payment phase and delivery phase:}

In the payment phase, it carries the payment for goods and settles account through the Sun Credit Bank. In the delivery phase, it has Yale Trucking Company to handle the stipulation. It's supervising and controlling transactional process is capable of managing and tracking the orders. Customers can examine the status of their orders on the web any time.

We summarize e-Chemical in the following three issues:

(i) Using Information technology: e-Chemical amalgamates the increasing number of suppliers, new trades and account settlements with the on-line trading. As a consequence, e-Chemical solves the poor efficiency problem in the supply chain of chemical trade.

(ii) Cooperative partnership: e-Chemical closely cooperates with chemical trade suppliers and retailers in making its e-commerce successful. It increases its marketability by establishing cooperative partnership with SOCMA and NACD. Furthermore, it joins alliance in technology and logistic services with IBM, Sun Credit Bank and Yale Trucking.

(iii) Confidential and neutral position: e-Chemical has gained good reputation for keeping confidential and neutral. Account users have to go through multi-tiered authentication to enter the highly secured website, and all transactional information are kept confidence along with the user registry.

\subsection{PlasticsNet}

PlasticsNet (www.plasticsnet.com) is the earliest electronic commercial center of the plastic trade in U.S.A. Since March of 1999, it has more than 30,000 registered online users, provides more than 90,0000 services monthly, and more than 165 suppliers in sales, marketing, advertising, etc. It has grown from a trading community and information center to a market with comprehensive e-commerce capability. PlasticsNet has gathered thousands of products form more than 200 
suppliers. It serves as a hub of information and trade opportunities for both sellers and buyers in the plastic industry.

\section{Information phase}

In this information phase of the B2B E-Market Model, PlasticsNet offers abundant information and service including a search engine, websites of suppliers, the largest on-line classified advertisement database in the plastic industry, a education database, issuance of sales statistics, a technology forum and a technology catalogue of the plastic industry.

\section{Negotiation Phase:}

It offers different trade mechanisms depending on the category type of the merchandise. It also provides functions to manage account receivables for the on-line trade transactions. PlasticsNet also provides auction and reversed auction mainly for the surplus, the aged products, or the uncommon products.

\section{Payment phase and delivery phase;}

It offers back-end support services such as information tracking, billing, account receivables management, etc.

We summarize PlasticsNet in the following three issues:

(i) Using Information technology: PlasticsNet has designed an office system particularly for the buyers. This back end support service has revolutionized the traditional trade by automating the link between accounting and data storage system, thus allowing users to order goods from multiple sellers with a single form.

(ii) Cooperative partnership: PlasticsNet's partners include Heller Financial, JD Edwards, etc.

(iii) Confidential and neutral position: PlasticsNet uses customer codes for its registered members to protect the identity and confidentiality. It also allows a computerized price quoting system, where both parties are unaware of the other. Users can obtain the price and information from automatic briefing and classification.

There are commonalities and differences in the B2B electronic markets between the America and China. From the B2B E-Market Model perspective, we find that The e-markets in both nations provide abundant of information, multiple trading functions and personalized services to satisfy customer's needs.

The e-markets in both nations focus on providing secure and reliable transactional processes. While Chinese e-market puts emphasis on supervising and controlling the transactional process to avoid intentionally delayed shipments and payments, American e-market stresses on the confidentiality of its members and the trades along with information tracking and inquiry systems.

Information technology is deployed in the American e-markets to respond to the poor efficiency in the supply chain. e-Chemical has integrated the increasing number of suppliers, new trades and account settlement together. PlasticsNet has a revolutionized computerized office system particularly for the buyers, which links 
the accounting and the data storage system allowing users to order goods from many sellers with a single form. American e-markets have combined the transactional processes with their enterprise information systems, thus improving the value chains of the enterprises. The Chinese e-markets are still only limited to managing and controlling of the transactional process to ensure the reliable execution of the contract.

The e-markets in both nations put efforts in establishing cooperative partnership network with banks and logistic parties. American e-markets are also creating alliances with others in their own industry to expand and strengthen the market share.

\section{Conclusion}

The evolving B2B e-market in China defines a new challenging field for research within e-commerce. To facilitate the development, we have attempted to approach the strategic value creation of B2B e-market in real-life context, and to describe and analyze them in the relevant perspectives. Four points are made about the research on B2B e-markets in China.

First, after introducing the e-market development in China a case study of a successful on-line B2B e-market is presented. It illustrates the performance of ebusiness strategy in the transactional processes of e-markets. The critical strategy components emerge from the analysis of e-commerce process. They are personalized and customized services, the structure and control of transactional process, and strategic network. Both payment and delivery are important business activities that reflect the effectiveness of the business strategies.

Second, we analyze different types of e-commerce activities and illustrate the value creation factors corresponding to the strategies. The B2B E-Market Model based on the e-commerce process is proposed to study e-commerce activities and strategy focus within the context of the four phases: information, negotiation, payment, and delivery. It enables us to identify and characterize the critical strategy and activities rooted in the e-commerce process. The controlling complexity and the process dimension are used to examine and study CCEC.com's transaction process for Security and Trust in B2B e-market.

Third, we apply the B2B E-Market Model to e-markets in U.S.A. and found common characteristics. The common characteristics are the support of abundant information on products and services to satisfy customer's needs. It is a place that gathers all information and provides multi-functions in trading. It focuses on the security, reliability and speed of the transactional process. It accentuates the development of the partners relationship and partners information network to support the transactional process. The difference is the application of the network and information technology for the transactional process. In U.S.A. the e-markets are to resolve the inefficiency of the supply chain, while in China they are only for monitoring and controlling. 
Overall, the present analysis indicates that B2B e-markets in China are still in their formative stages. It is noticeable that the e-market value generation is associated with designing, building and managing transaction process.

\section{Acknowledgement}

This research has been supported by grants from the National Natural Science Foundation of China under Grant 70172034 and Humanities and Social Science Foundation of China University of Geosciences (Wuhan).

\section{References}

1. T. McCall, Worldwide business-to-business Internet commerce to reach $\$ 8.5$ trillion in 2005. Gartner Group, press release, March 13, 2001. www3.gartner.com/5_about/press_room/ pr20010313a.html

2. R. J. Glushko, An XML framework for agent-based e-commerce, Communications of the ACM 42(3), 106-114 (1999).

3. L. L. Henriott, Transforming supply chains into e-chains, Supply Chain Management Review Global Supplement, pp. 15-18, (1999).

4. C. Hsu and S. Pant, Innovative planning for electronic commerce and enterprises: $A$ reference model (Kluwer Academic Publishers, Massachusetts, 2000).

5. C. Hsu, Enterprise Integration and Modeling: The Metadatabase Approach (Kluwer Academic Publishers, Amsterdam, Holland and Boston, Mass, 1996).

6. S. S. Mecker, Internet supply chain management, Electronic News 48 (16 Aug. 1999).

7. M. Raghunathan and R, M. Madey, A firm-level framework for planning electronic commerce information systems infrastructure, International Journal of Electronic Commerce 4(1), 121-145 (1999).

8. Deloitte Consulting, The future of B2B: A new genesis (Deloitte, Touche, Tohmatsu, 2000), http://www.dc.com/pdf/b2b_genesis.pdf

9. Qizhi Dai and Robert J. Kauffman, Business Models for Internet-Based B2B Electronic Markets, International Journal of Electronic Commerce 6(4), 41-72 (2002).

10. Zhu Zhen, The study on vertical application model B2B e-Marketplace (University of International Business and Economics, Beijing, 2005), http://www.uibe,edu.cn/.

11. J. P. Bailey and J. Y. Bakos, An exploratory study of the emerging role of electronic intermediaries, International Journal of Electronic Commerce 1(3), 7-20 (spring 1997). 
12. J. Y. Bakos, Reducing buyer search costs: Implications for electronic marketplaces, Management Science 43(12), 1676-1692 (December 1997).

13. Wang Baohua and Liu Liwen, Supply Chain Based Business Models of NeutralB2B Emarketplace, Management Review 12, 28-32 (2005).

14. Jiang Yubin, A B2B E-procurement Model based on Intermediary Website Shanghai Management Science 6, 41-44 (2005).

15. Yan Zhonghua, Guan Shixu and Mi Jianing, The theoretic Study about the Confidence Mechanism of B2B Based on System, Technoeconomics \& Management Research 5 , 89-89 (2003).

16. J, Zhao, W. V. Huang, Z Zhu and F. Duserick, Perception and Adoption of E-Business with Enterprises in China, in: The Proceedinsg of the Fourth Wuhan International Conference on Electronic Business (WICEB 2005), Lake View Garden Hotel, Wuhan, P. R. China, 2005, (WICEB, Wuhan, 2005), pp. 631-641.

17. Juns, E-Commerce Development in China, Beijing Jens E-Commerce R\&D Center, Available: http:/www.juns.com.cn

18. I. H. Ansoff and E, J. McDonnell, Implanting Strategic Management (Prentice Hall International, Ltd, Hemmel Hempstead, 1990).

19. R. Maurer, Using Resistance to Build Support for Change, The Journal for Quality and Participation, 19(3), 56-66 (1996).

20. R. P. Rumelt, Inertia and Transformation, in: Resource- Based and Evolutionary Theories of the Firm edited by C. A. Montgomery (Kluwer Academic Publishers, Boston, 1995), pp. 101-132.

21. X. P. Jiang, Electronic Commerce and Cyber-marketing, (Beijing, Tsinghua University Press 1998).

22. CCEC.com, (2002), http:// www.ccec.com.

23. D. Selz and P. Schubert, Web assessment-a model for the evaluation and the assessment of successful electronic commerce applications, in: Proceedings of the ThirtyEighth Annual Hawaii International Conference on System Sciences. Big Island, Hawaii, 2005, edited by Sprague, R. H. Jr. (IEEE, Piscataway, NJ, 2005), pp. 222-231. 